\title{
Evaluating a couple-based intervention addressing sexual concerns for breast cancer survivors: study protocol for a randomized controlled trial
}

Jennifer Barsky Reese ${ }^{1 *}$ (D), Lauren A. Zimmaro', Stephen J. Lepore ${ }^{1,2}$, Kristen A. Sorice $^{1}$, Elizabeth Handorf ${ }^{3}$, Mary B. Daly ${ }^{4}$, Leslie R. Schover ${ }^{5}$, Deborah Kashy ${ }^{6}$, Kelly Westbrook ${ }^{7}$ and Laura S. Porter ${ }^{8}$

\begin{abstract}
Background: Sexual concerns are distressing for breast cancer survivors and interfere with their intimate relationships. This study evaluates the efficacy of a four-session couple-based intervention delivered via telephone, called Intimacy Enhancement (IE). The IE intervention is grounded in social cognitive theory and integrates evidence-based techniques from cognitive behavioral couple therapy and sex therapy to address survivors' sexual concerns and enhance their and their partners' sexual, relationship, and psychological outcomes.

Methods: This trial is designed to evaluate the efficacy of the IE intervention in improving survivors' sexual function, the primary study outcome. Secondary outcomes include survivors' sexual distress, partners' sexual function, and survivors' and partners' relationship intimacy and quality as well as psychological distress (depressive symptoms and anxiety symptoms). Additional aims are to examine whether treatment effects on patient sexual function are mediated by sexual communication and self-efficacy for coping with sexual concerns and to explore whether survivor age and race/ethnicity moderate intervention effects on survivors' sexual function. Eligible adult female breast cancer survivors reporting sexual concerns and their intimate partners are recruited from two academic sites in the USA and are randomized to either the IE intervention or to a control condition of equal length offering education and support around breast cancer-related health topics (Living Healthy Together). The target sample size is 120 couples. Self-report outcome measures are administered to participants in both conditions at baseline (T1), post-treatment (T2), 3 months post-treatment (T3), and 6 months post-treatment (T4).

Discussion: Evidence-based interventions are needed to address sexual concerns for breast cancer survivors and to enhance their and their intimate partners' sexual, relationship, and psychological well-being. This randomized controlled trial will allow us to examine the efficacy of a novel couple-based intervention delivered via telephone for breast cancer survivors experiencing sexual concerns and their intimate partners, in comparison with an attention control. Findings of this study could influence clinical care for women with breast cancer and inform theory guiding cancer-related sexual rehabilitation.
\end{abstract}

Trial registration: ClinicalTrials.gov, NCT03930797. Registered on 24 April 2019.

Keywords: Breast cancer, Sexual dysfunction, Intimacy, Telephone-based, Randomized controlled trial

\footnotetext{
* Correspondence: Jennifer.Reese@fccc.edu

${ }^{1}$ Cancer Prevention and Control Program, Fox Chase Cancer Center, 333

Cottman Avenue, Philadelphia, PA 19111, USA

Full list of author information is available at the end of the article
}

(c) The Author(s). 2020 Open Access This article is distributed under the terms of the Creative Commons Attribution 4.0 International License (http://creativecommons.org/licenses/by/4.0/), which permits unrestricted use, distribution, and reproduction in any medium, provided you give appropriate credit to the original author(s) and the source, provide a link to the Creative Commons license, and indicate if changes were made. The Creative Commons Public Domain Dedication waiver (http://creativecommons.org/publicdomain/zero/1.0/) applies to the data made available in this article, unless otherwise stated. 


\section{Background}

Nearly one-third of all new cancer diagnoses in women are for breast cancer [1]. The majority of women are diagnosed with localized breast cancer, for which the 5year survival rate is 99\% [1]. Advances in detection and treatment have improved survival for breast cancer, yet these life-extending treatments can come at a considerable cost for survivors' intimate relationships [2, 3], which are often the cornerstone of their support systems. As many as $70 \%$ of breast cancer survivors report sexual concerns related to cancer diagnosis or treatment $[4,5]$. Common concerns include those that are biological (e.g., vaginal dryness, pain during sex) [6-8], psychological (e.g., loss of sexual desire) $[9,10]$, or social in nature (e.g., changes in partnered sexual activity) [1114]. Some of the most chronic and distressing sexual concerns for breast cancer survivors result from the estrogen suppression effects of chemotherapy, hormone therapy (e.g., aromatase inhibitors), and ovarian suppression $[6,15-17]$. In addition, post-surgery body changes, including the loss of breast and nipple sensitivity, can interfere with sexual activity and impede women's sexual arousal, a key component of their sexual function $[8,9$, $18,19]$. Loss of sexual desire is among the most problematic issues because it can significantly disrupt women's intimate relationships [20]. In turn, relationship factors can be strong predictors of sexual function $[7$, $12,21,22]$.

In contrast with many areas of health-related quality of life (QOL) that tend to improve over time, sexual concerns often persist for years after breast cancer survivors complete their primary treatments $[5,23-25]$. As a result, many breast cancer survivors and their partners may wish to resume a satisfying intimate relationship after treatment ends but encounter difficulties in doing so. If unaddressed, sexual concerns can lead to clinically significant psychological distress $[5,20]$ and may compromise survivors' relationships and quality of life $[2,17$, 26]. By contrast, there is evidence that addressing sexual concerns can have positive benefits not only for the survivors' sexual outcomes but also for other aspects of their and their partners' individual and relationship wellbeing [27-30]. In light of such findings, reviews of interventions in this area have concluded that the most effective interventions for addressing breast cancer survivors' sexual concerns tend to be those that are couple-based [27, 31]. To summarize, sexual concerns detract from the well-being of breast cancer survivors, whereas addressing such concerns might assist with preserving survivors' well-being while also benefiting their partners.

A couple-based intervention that systematically involves the partner may be a highly effective tool for addressing survivors' sexual concerns and enhancing their sexual function for several reasons [31-34]. First, breast cancer-related sexual concerns are most often experienced in the context of partnered sexual activity $[15,23]$. Therefore, survivors may benefit from guidance in putting physical aids (e.g., vaginal lubricants) and behavioral skills (e.g., communication skills) into practice in their intimate relationships [35-39]. Second, partners of breast cancer survivors commonly report sexual function problems [40] as well as difficulties in adjusting to their partners' sexual and body changes [11]. For instance, they may avoid touching their partner's breast or chest area or sexual activity altogether out of fear that they may hurt their partner physically or burden her with sexual demands. If not addressed, such factors could compromise survivors' efforts at coping effectively with sexual problems. Third, breast cancer survivors are most likely to discuss their sexual concerns with their intimate partners compared to other social outlets [41] and report a preference to have their partners involved in sexuality interventions [20]. Despite these factors, few studies of sexuality interventions in breast cancer have targeted couples by systematically including partners $[42,43]$.

Therefore, this study aims to evaluate a couple-based intervention designed to address sexual concerns for breast cancer survivors. The intervention, called Intimacy Enhancement (IE), is designed to be delivered via telephone to reduce participant burden and increase accessibility. The IE intervention is grounded in social cognitive theory [44] which posits that self-efficacy, i.e., the confidence that one can successfully complete a behavior, is a key predictor of accomplishing that behavior $[45,46]$. Self-efficacy has been shown to be a critical process underlying successful behavior change interventions in cancer $[47,48]$ that is best targeted through skills practice [46]. The IE intervention integrates skills practice and applies effective practices drawn from cognitive behavioral couple therapy (e.g., communication skills training) $[49,50]$ and sex therapy (e.g., sensate focus) [51, 52]. This intervention was adapted from a similar intervention initially developed for use with colorectal cancer survivors and their partners after finding promising effects on a range of patient and partner sexual and relationship outcomes [53, 54]. The adaptation was informed by a qualitative research study with breast cancer survivors to optimize the relevance of the educational content and of the skills training and practice for this new population [20].

We initially conducted a randomized pilot trial of the IE intervention in a sample of breast cancer survivors and their intimate partners and found support for the intervention's feasibility and acceptability as well as promising effects on key sexual and psychosocial outcomes [55]. We thus planned the current full-scale trial to evaluate the IE intervention's efficacy, investigate 
mediators of treatment effects, and explore potential intervention moderators. This trial compares the IE intervention with a previously tested attention control condition providing breast cancer-related education and support called Living Healthy Together (LHT). The IE intervention skills training activities are designed to increase patients' self-efficacy for coping with sexual concerns and improve their ability to communicate with their partners about sex; our pilot work found evidence supporting these treatment effects [55]. We therefore expect that increased self-efficacy for coping with sexual concerns and improvements in sexual communication will be mechanisms through which the IE intervention improves patient sexual function, and will test this in mediation analyses. The IE intervention appears to be acceptable and relevant across a diverse sample of patients of various ages and racial/ethnic groups. However, it is possible that the age and race/ethnicity of participants could influence sexual relationships [22, 56-60] and thus might interact with the IE intervention. We will therefore examine this in exploratory moderator analyses. This manuscript describes the study protocol for a multisite randomized controlled trial evaluating the IE intervention, a couple-based intervention addressing sexual concerns for post-treatment breast cancer survivors reporting sexual concerns.

\section{Study aims}

The specific aims of this study are illustrated in Fig. 1 and are as follows:

1. To evaluate whether the IE intervention leads to a significantly greater increase in patient sexual function from pre-treatment to post-treatment and at 3 and 6 month follow-ups compared to the LHT condition (Aim 1; Primary).
2. To evaluate whether the IE intervention leads to significantly greater improvements in partner sexual function (Aim 2a; Secondary), patient sexual distress (Aim 2b; Secondary), patient/partner relationship intimacy/quality, and psychological distress (Aim 2c; Secondary) from pre-treatment to post-treatment and at 3 and 6 month follow-ups, compared to the LHT condition.

3. To evaluate whether increases from pre- to posttreatment in patient sexual communication and self-efficacy for coping with sexual concerns mediate the beneficial effects of the IE intervention on patient sexual function at the 3 and 6 month follow-ups (Aim 3; Secondary).

4. To explore whether age $(\leq 45$ versus $>45$ at diagnosis) and race/ethnicity (White versus nonWhite) moderate intervention effects on the primary outcome of patient sexual function (Aim 4; Exploratory).

\section{Methods/design Study design}

A two-group randomized controlled trial design with pre-test and repeated post-test measures is used to accomplish the study aims. Women with breast cancer $(N=120)$ and their partners are randomized to one of two intervention conditions with equal allocation: Intimacy Enhancement (IE) or Living Healthy Together (LHT). Randomization is stratified by age at diagnosis and recruitment site. Both interventions are manualized, of equivalent duration, and delivered by a trained counselor to the couples jointly over the telephone. Web-based self-report outcome measures are administered to participants at baseline (T1), post-treatment (T2), 3 months post-treatment (T3), and 6 months posttreatment (T4). The study design is guided by the

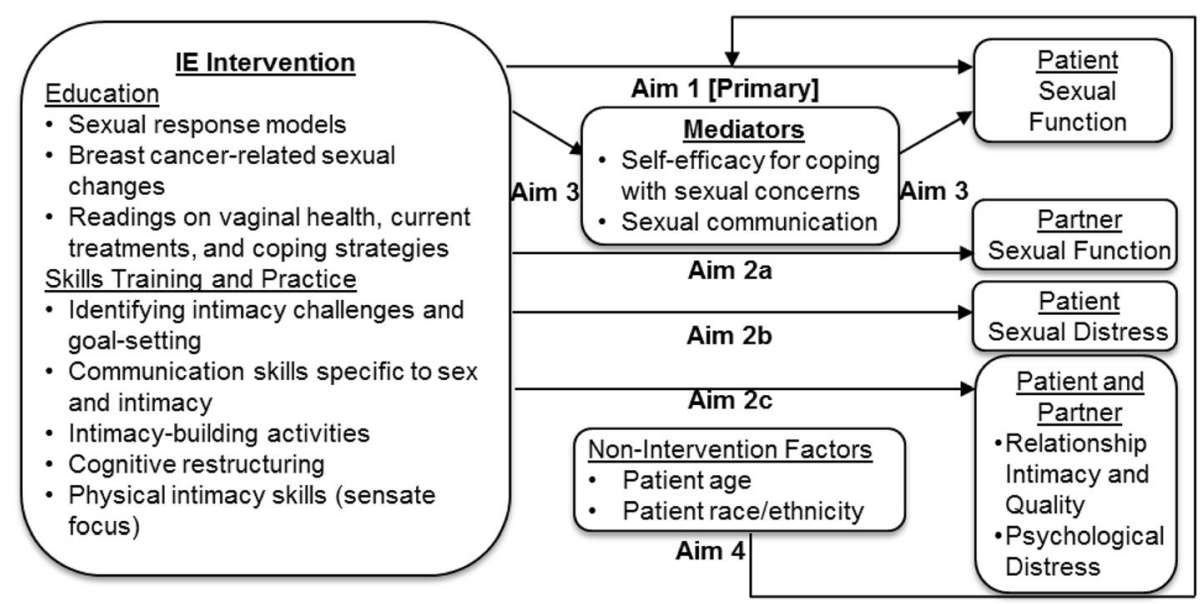

Fig. 1 Study conceptual schematic 
Consolidated Standards of Reporting Trials (CONSORT) criteria [61], and the project flow is shown in Fig. 2. The Standard Protocol Items: Recommendations for Interventional Trials (SPIRIT) guidelines [62] have been followed for this protocol, and the schedule of enrollment, interventions, and assessments is shown in Table 1. The SPIRIT checklist is provided as an additional file (see Additional file 1). All items from the current registry can be found within this protocol. Patient recruitment and data collection began in May 2019.

\section{Participants}

Eligibility inclusion criteria are as follows: female adults who have a medically confirmed diagnosis of localized breast cancer (stages T1-T4, N0-N1, and M0); age $\geq 18$ years; completed active treatment (surgery, chemotherapy, immunotherapy/targeted therapy, radiation therapy) 6 months to 5 years prior (current endocrine therapy use is acceptable); live with a partner (same or opposite sex) $\geq 6$ months and in a relationship that could involve sexual activity; partner or spouse age $\geq 18$ years; and report sexual concerns, as determined by scores $\geq 3 / 10$ on an item adapted from the Patient Care Monitor (PCM) [63], a reliable indicator of sexual concerns for women with breast cancer [2]. Exclusion criteria are the following: patient has a past or current history of cancer other than non-melanoma skin cancer including a prior breast cancer; patient or partner cannot speak and read in English; patient and partner do not have reliable telephone access; patient or partner has a hearing impairment that precludes participating in a telephone intervention; patient or partner has an Eastern Cooperative Oncology Group (ECOG) [64] score $>2$ or is deemed medically unable to participate; patient has overt cognitive dysfunction or psychiatric disturbance; couple is currently in marital/couple therapy; patient is currently pregnant; and partner does not agree to participate.

\section{Procedures}

\section{Screening and consent}

Patients are recruited through Fox Chase Cancer Center (FCCC) and Duke University Medical Center (DUMC), National Cancer Institute (NCI)-designated comprehensive cancer centers in the USA located in urban or suburban locations. Potentially eligible candidates are identified from each provider's clinic schedules, institution tumor registries, or clinician referral. Introductory study letters are sent to preliminarily eligible patients. Patients who do not decline further contact are contacted by a member of the study team who provides information about the study, screens the patient for eligibility, and reviews study procedures with the couple. Study advertisements supplement mailing-based recruitment. Recruiting couples is quite challenging $[65,66]$. If necessary, we will also expand recruitment efforts by working with community partners who provide support services to patients with cancer.

Consent is obtained using web-based forms, although participants are given the option to complete paperbased consent forms. Consent is considered complete when both members of the couple consent. Patients and partners receive a total possible compensation for the study of $\$ 140$ per person or $\$ 280$ per couple in either gift card or debit card form. Retention in our pilot trial was excellent [55], and we are employing similar methods to reduce participant burden and enhance retention in this trial, including web/mail-based surveys, telephone sessions, and flexible scheduling of sessions.

\section{Data collection}

Data collection is completed using Research Electronic Data Capture (REDCap), a secure, Health Insurance Portability and Accountability Act (HIPAA)-compliant web-based application used routinely in randomized controlled trials. Data collection using REDCap could reduce error due to manual data entry. Forms are routinely checked for quality. Participants without computer access can complete measures using paper and pencil versions. We have selected 3 and 6 month follow-ups to facilitate the evaluation of maintenance of IE intervention effects over a 6-month period, during which sexual concerns would otherwise likely be stable [2]. Various methods are employed to keep participant data confidential and secure including using password-protected files, limiting access to only those on the study team

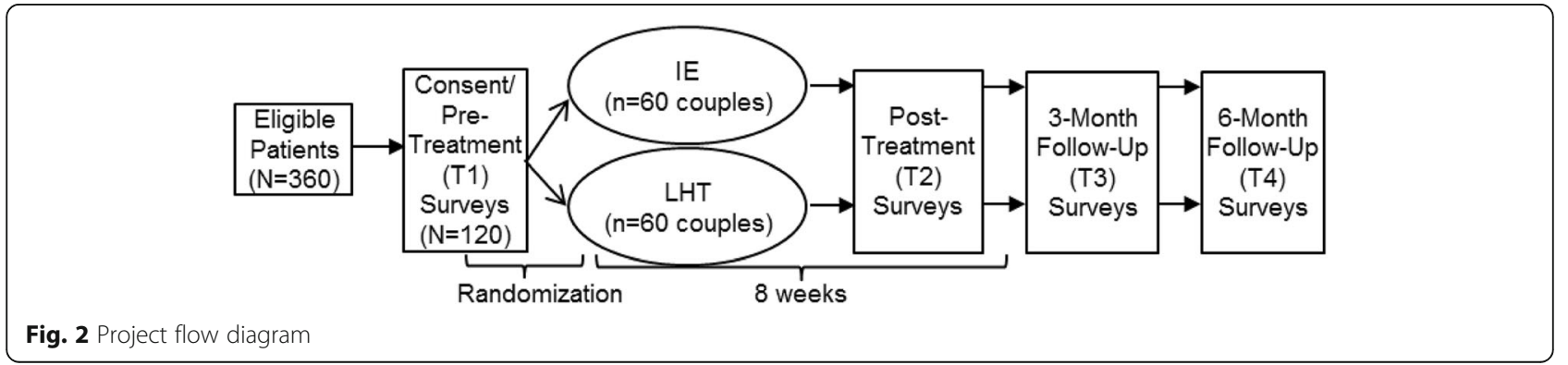


Table 1 Schedule of enrollment, interventions, and assessments

\begin{tabular}{|c|c|c|c|c|c|c|}
\hline & \multirow{2}{*}{$\begin{array}{l}\text { Enrollment } \\
\text { Eligibility } \\
\text { T0 }\end{array}$} & \multirow{2}{*}{$\begin{array}{l}\text { Allocation } \\
\text { Baseline } \\
\text { T1 }\end{array}$} & \multicolumn{4}{|c|}{ Post-allocation } \\
\hline & & & $\begin{array}{l}\text { Sessions } \\
1-4\end{array}$ & $\begin{array}{l}\text { Post-Session } \\
\text { T2 }\end{array}$ & $\begin{array}{l}3 \text { Months } \\
\text { T3 }\end{array}$ & $\begin{array}{l}6 \text { Months } \\
\text { T4 }\end{array}$ \\
\hline \multicolumn{7}{|l|}{ ENROLLMENT } \\
\hline Eligibility screen & $x$ & & & & & \\
\hline Informed consent & & $x$ & & & & \\
\hline Allocation & & $x$ & & & & \\
\hline \multicolumn{7}{|l|}{ INTERVENTIONS } \\
\hline IE intervention & & & $x$ & & & \\
\hline LHT intervention & & & $x$ & & & \\
\hline \multicolumn{7}{|l|}{ MEASURES } \\
\hline \multicolumn{7}{|l|}{ Primary outcome } \\
\hline $\begin{array}{l}\text { Female Sexual Function Index } \\
(\text { FSFI) }\end{array}$ & & $x$ & & $x$ & $x$ & $x$ \\
\hline \multicolumn{7}{|l|}{ Secondary outcomes } \\
\hline $\begin{array}{l}\text { Male partners: International Index of Erectile Function (IIEF) } \\
\text { Female partners: FSFI }\end{array}$ & & $x$ & & $x$ & $x$ & $x$ \\
\hline $\begin{array}{l}\text { Female Sexual Distress Scale- } \\
\text { Revised (FSDS-R) }\end{array}$ & & $x$ & & $x$ & $x$ & $x$ \\
\hline Miller Social Intimacy Scale (MSIS) & & $x$ & & $x$ & $x$ & $x$ \\
\hline $\begin{array}{l}\text { Dyadic Adjustment Scale-7 item } \\
\text { (DAS-7) }\end{array}$ & & $x$ & & $x$ & $x$ & $x$ \\
\hline Patient Health Questionnaire-9 item (PHQ-9) & & $x$ & & $x$ & $x$ & $x$ \\
\hline Generalized Anxiety Disorder 7-item (GAD-7) & & $x$ & & $x$ & $x$ & $x$ \\
\hline \multicolumn{7}{|l|}{ Mediators } \\
\hline Dyadic Sexual Communication Scale (DSCS) ${ }^{a}$ & & $x$ & & $x$ & & \\
\hline Self-efficacy (for coping with sexual concerns) ${ }^{a}$ & & $x$ & & $x$ & & \\
\hline
\end{tabular}

${ }^{\mathrm{a} A}$ patient-only measure

who require identifiable data, and using de-identified data when possible.

\section{Randomization}

This study uses 1:1 blocked randomization (group size $4)$, stratifying by age at diagnosis $(\leq 45$ versus $>45)$ [9, $56]$ and recruitment site. The project biostatistician generated the randomization sequence, and treatment assignment occurs through REDCap. Randomization occurs once the couple has completed their baseline assessment and is scheduled for their first intervention session. Couples receive sealed study materials and are instructed to leave the envelopes sealed until Session 1 (to minimize unequal drop-out after participants know their allocated study arm). As with most behavioral interventions, study interventionists, intervention supervisors (site principal investigators [PIs]), and participants are not blind to study condition. To facilitate unbiased data collection and analysis, the following steps are taken: (1) the study biostatistician will conduct outcome data analyses on data in which the study condition is masked; (2) baseline (T1) surveys are administered prior to randomization; and (3) outcome data collection is completed in an automated fashion using REDCap, minimizing the need for contact with participants to collect study data. During the annual review of adverse events, the presence of significant between-group differences could potentially warrant unmasking of the study conditions by the study biostatistician.

\section{Measures \\ Overview of measures}

The measures used in this trial have been shown to be reliable and valid when used in studies of patients with cancer. In addition, to reduce the burden of survey completion for study participants, brief surveys have been selected and abbreviated or short-form versions of measures are selected when available. Full descriptions of the outcome measures (i.e., outcome definitions) are shown in Table 2.

\section{Patient sexual function (primary outcome measure)}

Sexual function is assessed using the Female Sexual Function Index (FSFI [67]), a widely used sexual 
Table 2 Outcome definitions

\begin{tabular}{|c|c|c|c|c|}
\hline Domain & Measure & Metric & Method of aggregation & $\begin{array}{l}\text { Time points (for } \\
\text { comparison) }\end{array}$ \\
\hline & Primary outcome & & & \\
\hline \multirow[t]{2}{*}{$\begin{array}{l}\text { Sexual } \\
\text { function }\end{array}$} & $\begin{array}{l}\text { Female Sexual Function Index } \\
(\text { FSFI) })^{\mathrm{a}}\end{array}$ & Difference in change scores & Mean score & $\begin{array}{l}\mathrm{T} 1-\mathrm{T} 2 ; \mathrm{T} 1-\mathrm{T} 3 ; \mathrm{T} 1- \\
\mathrm{T} 4\end{array}$ \\
\hline & Secondary outcomes & & & \\
\hline $\begin{array}{l}\text { Sexual } \\
\text { function }\end{array}$ & $\begin{array}{l}\text { Male partners: International Index of } \\
\text { Erectile Function (IIEF) } \\
\text { Female partners: FSFI }\end{array}$ & $\begin{array}{l}\text { Difference in change scores; } \\
\text { difference in proportions }\end{array}$ & $\begin{array}{l}\text { Mean score; proportions by } \\
\text { clinical cut-off score }\end{array}$ & $\begin{array}{l}\mathrm{T} 1-\mathrm{T} 2 ; \mathrm{T} 1-\mathrm{T} 3 ; \mathrm{T} 1- \\
\mathrm{T} 4\end{array}$ \\
\hline Sexual distress & $\begin{array}{l}\text { Female Sexual Distress Scale- } \\
\text { Revised (FSDS-R) }\end{array}$ & Difference in change scores & Mean score & $\begin{array}{l}\mathrm{T} 1-\mathrm{T} 2 ; \mathrm{T} 1-\mathrm{T} 3 ; \mathrm{T} 1- \\
\mathrm{T} 4\end{array}$ \\
\hline $\begin{array}{l}\text { Relationship } \\
\text { intimacy }\end{array}$ & Miller Social Intimacy Scale (MSIS) & Difference in change scores & Mean score & $\begin{array}{l}\mathrm{T} 1-\mathrm{T} 2 ; \mathrm{T} 1-\mathrm{T} 3 ; \mathrm{T} 1- \\
\mathrm{T} 4\end{array}$ \\
\hline $\begin{array}{l}\text { Relationship } \\
\text { quality }\end{array}$ & $\begin{array}{l}\text { Dyadic Adjustment Scale-7 item } \\
\text { (DAS-7) }\end{array}$ & Difference in change scores & Mean score & $\begin{array}{l}\mathrm{T} 1-\mathrm{T} 2 ; \mathrm{T} 1-\mathrm{T} 3 ; \mathrm{T} 1- \\
\mathrm{T} 4\end{array}$ \\
\hline $\begin{array}{l}\text { Psychological } \\
\text { distress }\end{array}$ & $\begin{array}{l}\text { Patient Health Questionnaire-9 item } \\
\text { (PHQ-9) }\end{array}$ & Difference in change scores & Mean score & $\begin{array}{l}\mathrm{T} 1-\mathrm{T} 2 ; \mathrm{T} 1-\mathrm{T} 3 ; \mathrm{T} 1- \\
\mathrm{T} 4\end{array}$ \\
\hline $\begin{array}{l}\text { Psychological } \\
\text { distress }\end{array}$ & $\begin{array}{l}\text { Generalized Anxiety Disorder 7-item } \\
\text { (GAD-7) }\end{array}$ & Difference in change scores & Mean score & $\begin{array}{l}\text { T1-T2; T1-T3; T1- } \\
\text { T4 }\end{array}$ \\
\hline
\end{tabular}

${ }^{\mathrm{a}} \mathrm{A}$ patient-only measure

function measure with established validity in breast cancer $[68,69]$. The FSFI is a 19-item multidimensional measure of sexual function in assessing various aspects of sexual function including desire, arousal, lubrication, orgasm, pain during sex, and sexual satisfaction. The total score will be used, as it reflects women's overall sexual function and because total FSFI scores are sensitive to increases in similar interventions $[42,43]$.

\section{Secondary outcome measures}

Partner sexual function Partner sexual function is assessed using the International Index of Erectile Function (IIEF) [70] if the partner is male or the FSFI [67], described previously, if the partner is female. The IIEF is a 15-item multidimensional measure of sexual function that assesses various aspects of male sexual function including desire, erectile function, orgasm, and sexual satisfaction. The IIEF is the most widely used measure to assess male sexual function and has been used successfully in a multitude of healthy and medical populations [71].

Patient sexual distress Patient sexual distress is assessed using the Female Sexual Distress Scale-Revised (FSDS-R [72]). The FSDS-R is a 13-item validated measure of female sexual distress designed for use in women's sexual medicine trials [72] that measures the degree of distress and dissatisfaction related to a woman's sex life over the past 30 days. The FSDS-R has been used in both observational and intervention studies with breast cancer survivors $[5,25,73]$.

Patient and partner relationship intimacy Patient and partner relationship intimacy is assessed using the Miller
Social Intimacy Scale (MSIS [74]). The MSIS is a 17item scale assessing emotional intimacy, closeness, and trust toward an individual's partner that has been used in trials assessing psychosocial and sexual couple-based interventions of psychosocial interventions for patients with cancer $[54,75,76]$.

Patient and partner relationship quality is assessed using the 7-item Dyadic Adjustment Scale (DAS-7 [77, 78]). The DAS-7 provides information on relationship quality comparable to that obtained when using the full 32-item measure and can distinguish between couples who are distressed versus well-adjusted on the full scale [78]. The DAS-7 has been used successfully in studies in breast cancer [79].

Patient and partner psychological distress Patient and partner psychological distress are assessed using the $\mathrm{Pa}$ tient Health Questionnaire-9 item (PHQ-9 [80]) and Generalized Anxiety Disorder 7-item (GAD-7 [81]), both of which are validated and commonly used measures to assess depression and anxiety, respectively, in cancer and other medical populations [82].

\section{Intervention mediators}

\section{Patient self-efficacy for coping with sexual concerns}

Patient self-efficacy with sexual concerns is assessed through three items measuring patients' confidence in their ability to communicate effectively about sexual concerns, deal effectively with sexual concerns, and enjoy sexual intimacy despite physical limitations. These items were developed using standard methods for constructing self-efficacy scales according to social cognitive theory [83] and have shown excellent psychometric 
properties when used as a single scale as well as sensitivity to the IE intervention [55].

\section{Patient sexual communication}

Patient sexual communication is assessed using 6 items from the Dyadic Sexual Communication Scale (DSCS [84]), which assesses the perceived quality of communication about sex in the context of the intimate relationships and has been used successfully in cancer studies $[53,85]$. Previously, we found that these 6 items (items 2 , $3,4,10,11$, and 12 ) had $95 \%$ correlation with the 13 -item scale in a sample of breast cancer survivors (Reese JB \& Handorf E: Establishing the reliability of an abbreviated 6-item dyadic sexual communication scale for use with breast cancer survivors, unpublished).

\section{Intervention moderators}

The potential moderators of patient age $(\leq 45$ versus $>45)$ at diagnosis and race/ethnicity (White versus non-White) will be assessed using medical records and patient selfreport, respectively. Age is selected as a moderator for the same reason as it is selected as a stratifier variable, in that younger and older women may differ in their sexual function $[9,56]$ and could thus differ in their response to the intervention. Race/ethnicity is included as a potential moderator because there is little data on whether couple-based sexuality interventions are equally effective in breast cancer survivors from different racial/ethnic backgrounds.

\section{Other measures}

Socio-demographic characteristics such as education, sexual orientation, marital and work status, race/ethnicity, income, and relationship length are assessed through self-report. Clinical patient characteristics including menopausal status and types and dates of treatments are obtained through medical chart review. Medical comorbidity data for patients and partners are obtained by a validated self-report comorbidity measure (Self-Administered Comorbidity Questionnaire; SCQ) (Sangha O, Stucki G, Liang MH, Fossel AH, Katz JN: The Self-Administered Comorbidity Questionnaire: a new method to assess comorbidity for clinical and health services research, unpublished). In addition, a brief measure is used to assess intervention credibility [86] in both conditions (i.e., logic, helpfulness, and competence of the counselor) after Session 1 and at the postintervention time point (T2).

\section{Study arms}

\section{Intervention overview}

Both intervention conditions are administered over the telephone to both members of the couple jointly and are designed to be of equal duration and to contain material of interest to both patients and partners. Both conditions are delivered according to a standard intervention protocol, consisting of an interventionist manual and corresponding participant handouts. All session calls are audio recorded. The first session for both interventions is designed to last approximately $75 \mathrm{~min}$, and the remainder to last 60 min each.

\section{Interventionists}

Interventions are conducted by interventionists with a master's or doctoral degree in a mental health field certified competent in delivery of the interventions by the PI. All interventionists complete an in-depth training protocol consisting of background readings on key topics including common sexual and non-sexual side effects of breast cancer treatment, sexual response [87], key techniques such as cognitive behavioral couple therapy [49] and sensate focus therapy [88], theoretical models [45, 89, 90], and cultural considerations [91, 92], and the intervention protocols (manuals, participant handouts); a training workshop which includes review of readings, protocols, and specific skills, role plays, and discussions; listening to and discussing full cases of each condition; and finally, completing full test cases of each condition and corresponding supervision. A key element of training is ensuring that the interventionists are able to maintain fidelity to each of the two intervention manuals while establishing rapport and therapeutic alliance. To this end, the interventionists complete session adherence forms after each session in order to capture information on their perceived completion of the intervention session components, the case conceptualization, and to identify difficulties they had in delivering the interventions as intended. These processes help catch possible "drift" in the delivery of intervention material over time or across conditions. Supervision with the PI (Reese) and Duke site PI (Porter) occurs regularly and includes review of session audio recordings and supervisor-completed adherence and performance forms, as well as discussions of related intervention delivery and case issues. A random selection of at least $10 \%$ of sessions will be reviewed to assess intervention fidelity by an independent reviewer not involved with the intervention delivery.

\section{Intimacy Enhancement (IE)}

The Intimacy Enhancement (IE) intervention incorporates education and training in skills for coping with sexual concerns. The IE intervention is designed to address women's sexual concerns that are physical (e.g., vaginal dryness), emotional (e.g., loss of libido), or interpersonal in nature (e.g., changes in sexual scripts due to breast changes) [93]. Content also integrates a framework for coping with sexual concerns that emphasizes flexibility in thoughts and behaviors, and encourages more inclusive thinking about how sex and intimacy are enacted 
Table 3 Intimacy Enhancement intervention session overview

\begin{tabular}{|c|c|c|c|}
\hline $\begin{array}{l}\text { Session } \\
\text { (length) }\end{array}$ & Title & Content & Home practice \\
\hline $\begin{array}{l}1 \\
(75 \mathrm{~min})\end{array}$ & Introduction to Intimacy Enhancement & $\begin{array}{l}\text { 1. Sexual response cycle } \\
\text { 2. Breast cancer effects on sex and intimacy } \\
\text { 3. Intimacy challenges and goal-setting } \\
\text { 4. Introduction to physical intimacy skills (sensate focus) } \\
\text { 5. Treatments and sexual aids }\end{array}$ & $\begin{array}{l}\text { 1. Read educational handouts } \\
\text { 2. Sensate focus Practice } 1\end{array}$ \\
\hline $\begin{array}{l}2 \\
(60 \mathrm{~min})\end{array}$ & Enhancing Intimacy Through Communication & $\begin{array}{l}\text { 1. Effective communication about sex and intimacy } \\
\text { 2. Challenges in communicating effectively about sex and intimacy } \\
\text { 3. Communication skills practice }\end{array}$ & $\begin{array}{l}\text { 1. Communication skills } \\
\text { practice } \\
\text { 2. Sensate focus Practice } 2\end{array}$ \\
\hline $\begin{array}{l}3 \\
(60 \mathrm{~min})\end{array}$ & $\begin{array}{l}\text { Enhancing Intimacy Through Thinking and } \\
\text { Doing }\end{array}$ & $\begin{array}{l}\text { 1. Positive and negative thought cycles } \\
\text { 2. Flexible and inflexible thinking about sex and intimacy } \\
\text { 3. Identifying and changing negative/inflexible thoughts } \\
\text { 4. Broadening range of intimate activities (intimacy-building activities) }\end{array}$ & $\begin{array}{l}\text { 1. Intimacy-building activities } \\
\text { 2. Sensate focus Practice } 3\end{array}$ \\
\hline $\begin{array}{l}4 \\
(60 \mathrm{~min})\end{array}$ & Planning Ahead for Intimacy & $\begin{array}{l}\text { 1. Review of skills and education } \\
\text { 2. Evaluate progress toward goals } \\
\text { 3. Plan for continued skills practice } \\
\text { 4. Anticipate and plan for challenges ("red flags" for maintaining } \\
\text { intimacy) }\end{array}$ & \\
\hline
\end{tabular}

within the relationship [89, 90]. The four sessions and their content and structure are described in Table 3. Participant handouts reinforce educational material, provide opportunities for interactive exercises, and reinforce skills learned during the sessions. Weekly home behavioral skills practice are reviewed at the beginning of each session, including proceeding through a stepped set of sensate focus exercises (i.e., non-demand sensual touching) [51], with the goal of reducing avoidance of physical intimacy and increasing comfort with sexual activity.

\section{Living Healthy Together (LHT)}

The LHT intervention focuses on delivering education and support across a range of topics relevant to women with breast cancer. Research has found that health-related concerns including social support, sleep and fatigue, stress, and diet are among the top concerns for breast cancer survivors [94, 95], and thus these topics were selected for inclusion. To increase participant engagement, the material in this condition includes participant self-assessment related to health habits and discussion of challenges in achieving or sustaining beneficial health behaviors during the sessions. The LHT intervention demonstrated excellent credibility and acceptability in a pilot study [55]. This condition includes education on breast cancer experience and finding support (Session 1), stress and stress management (Session 2), fatigue and sleep (Session 3), and nutrition and physical activity (Session 4). Couples in this condition are encouraged to engage with the material between sessions by completing readings, trying out strategies, and seeking out resources and information.

\section{Statistical plan}

\section{Overview of statistical analyses}

First, descriptive statistics will be used to characterize sample covariates. Outcome variables will be assessed for normality and, if necessary, normalizing transformations may be applied. We will determine whether the enrolled sample differs from eligible study refusers on key socio-demographic and clinical factors obtained during screening (e.g., age, treatments, severity of sexual concerns) using two-sample $t$ tests or chisquare tests. Study completers will also be compared to non-completers on these variables, and logistic regression will be used to understand what factors are predictive of drop-out. Variables showing significant imbalances will be included in subsequent models as covariates. We will account for missing data using multiple imputation by chained equations (MICE) [96-98], which provides valid inferences provided that the probability of having missing data (i.e., drop-out) only depends on the observed data (e.g., treatment arm, baseline sexual function). For primary and secondary outcome analyses, differences in mean change scores for the outcomes will be used (see Table 2 for outcome definitions). No interim analyses are planned.

\section{Primary aim}

The primary analysis will examine whether, relative to the LHT intervention, the IE intervention leads to greater increases in patient sexual function at all three post-treatment assessments in a mixed-effects regression model. Pre-treatment sexual function scores and time (categorical) will be included as covariates. Intervention by time interactions will test the intervention effect at each follow-up time. Subject-specific random intercepts will account for within-subject variability. Intervention effects on patient sexual function at each follow-up are tested using $F$ tests of combined main and interaction effects.

\section{Secondary aims}

Analyses of intervention effects on partner sexual function and patient sexual distress will use similar mixed- 
effects models as those described under the primary aim. Partner sexual function will generally be measured and analyzed using a male-specific scale. In additional analyses, potential same-sex partners' sexual function data will be handled by categorizing all scores as dysfunctional versus functional (using clinical cut-offs), and estimating the intervention effect via logistic mixed-effects regression models $[99,100]$, controlling for partner sex. Relationship intimacy and quality and psychological distress will be assessed using identical measures in both patients and partners. Multilevel modeling (MLM) [101] will be used to test for differences in these outcomes between the IE and LHT groups over time. These models include all main effects and interactions among time (categorical), treatment, and role (patient/partner). Models also include random intercepts for patients and partners, as well as the correlation between the intercepts (i.e., if a patient is high in average distress across time, is the partner also high in distress?). Models will include a time-specific correlation between the partners' residuals (i.e., if a patient is distressed at a particular time point, is the partner also distressed at that time?).

\section{Mediators and moderators}

We will evaluate whether pre-intervention to postintervention changes in either sexual communication and/or in self-efficacy for coping with sexual concerns mediate treatment effects on sexual function using the causal inference framework for mediation described by VanderWeele [102, 103]. Initial models will assess mediation at 3 months follow-up; if evidence of mediation is found, 6 months follow-up will be explored in separate models. Effects will be estimated via structural equation modeling, and covariates (age, race, etc.) will be included to account for possible mediator/outcome confounding. Separate models will be fit for the two proposed mediators.

We will explore whether both age $(\leq 45$ versus $>45)$ and race/ethnicity (White versus non-White) moderate the intervention effects. In separate models, we will add each moderator and interactions between the moderator, intervention, and time point to the model of Aim 1. A significant three-way interaction will provide evidence that the treatment effect differs by age or race. However, as this study is not powered to detect interactions, we will consider interaction effects with a magnitude $>(0.5$ * main effect) to be of interest.

\section{Sample size estimate/power calculations}

Power calculations are based on Aim 1. For patient sexual function, a change of 5 points would be clinically meaningful (scale range 2-36, standard deviation $[\mathrm{SD}] \approx$ $10)$. Based on prior data, we anticipate that the SD of the change scores will be 8.2 , and that there will be an attrition rate of $24 \%$, resulting in 92 analyzable couples at 6 months follow-up. We will therefore have $82 \%$ power to detect a difference of 5 points in change scores, assuming a two-sided test with 5\% type I error.

\section{Ethical aspects}

The trial has been approved by the Institutional Review Boards at Fox Chase Cancer Center (Protocol 18-1025) and Duke University Medical Center (Protocol Pro00100404). All study faculty and staff have been trained in principles of ethical conduct of human subjects' research and in compliance with study procedures. Study participants are informed that their participation or decision not to participate or to withdraw will not have an effect on their receipt of healthcare at their respective institutions. The financial incentives for participation are consistent with those offered in comparable couple-based studies and are meant to ethically compensate participants for completion of repeated study surveys. Given the minimal risk of this study, a Data and Safety Monitoring Board was deemed unnecessary. The institutional research review committees at the respective study sites review all study activities annually including ethical conduct, regulatory compliance, and recruitment and retention, and can initiate an independent study audit at any time. The study sponsor also monitors study progress annually including sufficient recruitment and retention. In addition, the investigator team meets at least monthly to discuss enrollment targets and treatment fidelity. The study coordinator is responsible for ensuring that data is complete from both sites and for tracking enrollment at both sites. Adverse events across conditions will be reviewed annually; issues with intervention delivery and other unintended consequences of either intervention are discussed during regular supervision meetings. Significant protocol modifications will be approved by relevant Institutional Review Boards and will be reported to relevant parties (e.g., ClinicalTrials.gov) in a timely fashion. Couples have the option of discontinuing their participation in the study at any time, and this is indicated in the consent forms. Adverse events will be reported immediately to the PI, tracked, and responded to according to regulatory guidelines. In the rare case of distress (individual or relational) so severe that continuation of the intervention sessions or of the study procedures is judged to interfere with the participant's well-being or timely receipt of necessary care, the couple will be counseled to discontinue and will be referred for appropriate care. There are no criteria for the modification of the study interventions. As harm from this type of study is rare, there are no provisions in place for ancillary, post-trial, or compensation for study-related harms. 


\section{Discussion}

Upon completion of this study, we will have provided a rigorous test of the efficacy of an innovative intervention addressing sexual concerns and enhancing the sexual, relationship, and psychosocial outcomes for breast cancer survivors and their partners. This intervention is unique from other couple-based interventions in cancer by focusing explicitly on the intimate relationship and by integrating the partner fully into the activities aimed at building couples' skills for coping with sexual concerns and enhancing intimacy. Results of this study will also provide information on theoretically based mediators of the IE intervention effects, and potential moderators of treatment efficacy.

The IE intervention has several important features that may enhance its impact, including a strong theoretical basis in social cognitive theory, incorporation of evidence-based skills practices from couple therapy and sex therapy, grounding in formative qualitative research with breast cancer survivors, and the use of a telephone format, which has several advantages over face-to-face and web-based options. Specifically, a telephone format may decrease barriers to access for couples who cannot make use of a comparable web-based intervention due to lack of Internet or computer access or literacy, and it makes it possible for couples to participate who would be unable to attend in-person visits due to geographical limitations, cost, or the burden of travel. This format may be particularly well-suited to the needs of posttreatment breast cancer survivors, who report interest in obtaining help for sexual concerns [104] but make fewer in-person visits, and may be preferred over face-to-face interventions for discussing sexuality [53].

This study has several strengths including the use of an active control condition that equates for interventionist time and attention, examination of a range of important patient and partner sexual, relationship, and psychological outcomes, and examination of treatment mediators and moderators. Understanding treatment mediators is important given that there is a paucity of research on mechanisms underlying the efficacy of sexual function interventions in cancer $[47,105]$, while exploring intervention moderators could help us determine whether to adapt the IE intervention to address the needs of certain breast cancer patient subgroups.

This study also has several limitations that should be considered. For instance, because both intervention conditions are designed for couples, only breast cancer survivors who are partnered may participate in the trial, thus excluding unpartnered survivors who have sexual concerns. In addition, although the trial is open to both opposite-sex and same-sex couples, given our past experience, we anticipate that most couples will likely be heterosexual. Thus, the study will not be powered to determine whether effects of the IE intervention could differ for patients by sexual orientation, although examining this would be an important step in advancing the research on evidence-based sexual function interventions for sexual and gender minority cancer survivors. Despite these limitations, this study represents a critical piece of a larger program of research that aims to advance clinical care through the development, evaluation, and dissemination of evidence-based interventions to improve the sexual health and QOL of those affected by cancer. The findings of this trial will be disseminated to researchers and the public through the study's entry on ClinicalTrials.gov, through publication in peer-reviewed journals, and through presentation of the findings to the scientific community at scientific conferences.

In conclusion, sexual concerns for breast cancer survivors frequently go unaddressed and evidence-based interventions are needed, particularly those that integrate survivors' partners. With the proposed study completed, we will be well-equipped to determine critical next steps in this program of research. For instance, if we find that the IE intervention is effective, we may consider expanding it for use with other cancer populations in need of evidencebased interventions addressing sexual concerns (e.g., head and neck cancer, patients with advanced cancer). We may also consider a pragmatic trial that would allow us to determine whether delivering this intervention in the "real world" could sustain effects. Depending on the findings from the mediation analyses, another interesting next step could be to examine whether individual component(s) of the IE intervention (e.g., communication skills training; sensate focus practice) would hold up against the full intervention in a controlled trial. Finally, findings of the moderator analysis could help us determine whether to consider adapting the IE intervention to address the needs of particular subgroups of patients with breast cancer.

\section{Trial status}

Both sites are actively recruiting participants for this trial. Recruitment for the trial began in May 2019 and is expected to continue until November 2022. This manuscript describes Version 6 of the study protocol, dated 07/02/2019.

\section{Supplementary information}

Supplementary information accompanies this paper at https://doi.org/10. 1186/s13063-019-3975-2.

Additional file 1. Detailed SPIRIT checklist of items for the study.

\section{Abbreviations}

DAS-7: Dyadic Adjustment Scale-7 item; DSCS: Dyadic Sexual Communication Scale; DUMC: Duke University Medical Center; ECOG: Eastern Cooperative Oncology Group; FCCC: Fox Chase Cancer Center; FSDS-R: Female Sexual Distress Scale-Revised; FSFI: Female Sexual Function Index; GAD7: Generalized Anxiety Disorder 7-item; IE: Intimacy Enhancement; IIEF: International Index of Erectile Function; LHT: Living Healthy Together; 
MLM: Multilevel modeling; MSIS: Miller Social Intimacy Scale; PCM: Patient Care Monitor; PHQ-9: Patient Health Questionnaire-9 item; PI: Principal investigator; QOL: Quality of life; SCQ: Self-Administered Comorbidity Questionnaire; SD: Standard deviation

\section{Authors' contributions}

Authorship was determined using the standards endorsed by the International Committee of Medical Journal Editors. There is no plan for the use of medical writers. JBR is the principal investigator of the study and developed a first draft of this manuscript. LAZ is a post-doctoral fellow and study interventionist and contributed to the drafting of the procedures section and to the development of the intervention protocol. SJ, MBD, KW, and LSP are co-investigators on the trial; LSP is also site principal investigator for the Duke recruitment site. SJL reviewed and provided feedback on an earlier draft of the manuscript and contributed to the fidelity measures, study design, and selection of outcome measures. KAS is the project coordinator and contributes to the design and implementation of procedures for study data collection, randomization, recruitment, and consent, and modifies the study protocol and procedures as needed; she regularly monitors data correctness and completion. LSP played a key role in the development and refinement of the intervention protocols and of conception of the IE and LHT interventions in earlier work and also contributed to study design decisions including outcome measures selection. $\mathrm{EH}$ is the study biostatistician and contributed to the study design and analytic plan. MBD and KW assisted with conceiving medical aspects of the study such as eligibility determination. LRS is a study consultant and contributed to the IE intervention content. DK is a study consultant and contributed to the analytic plan. All authors read and approved the final manuscript.

\section{Funding}

The trial described in this publication is supported by the National Cancer Institute (NCl) of the $\mathrm{NIH}$ under Award Number R01CA222124. Additional funding that supports this work includes P30CA006927 and T32-CA-009035, also from the $\mathrm{NCl}$. The funding body had no role in the design of the study, in the collection, analysis, or interpretation of data, or in the writing of the manuscript. The mailing address for the NCl is BG 9609 MSC 9760; 9609 Medical Center Drive; Bethesda, MD 20892-9760.

\section{Availability of data and materials}

Study data and relevant materials from the trial described in this manuscript will be retained and archived by the primary study site for a minimum of 3 years after study completion as per National Institutes of Health (NIH) policy on record retention. There are no plans for publicly sharing the trial data. No materials (biological specimens) are collected as part of this trial.

\section{Ethics approval and consent to participate}

This study was approved by the Institutional Review Boards at Fox Chase Cancer Center (Protocol 18-1025) and Duke University Health System (Protocol Pro00100404). Informed consent will be obtained by all study participants. Consent elements are standard for behavioral intervention trials, with several exceptions: (1) consent forms make the distinction between patients and partners for medical records data, in that patient medical record data are accessed for patients' medical characteristics whereas this is not done for partners in the trial; (2) sessions are audio recorded and the consent form stipulates this as necessary for participation. No biological specimens are collected as part of this protocol and as such no consent is necessary for the use of biological specimens. Consent is not obtained to use data in ancillary studies.

\section{Consent for publication}

Not applicable.

\section{Competing interests}

The authors declare that they have no competing interests.

\section{Author details}

${ }^{1}$ Cancer Prevention and Control Program, Fox Chase Cancer Center, 333 Cottman Avenue, Philadelphia, PA 19111, USA. ²Department of Social and Behavioral Sciences, College of Public Health, Temple University, 1301 Cecil B. Moore Avenue, Ritter Annex, Philadelphia, PA 19122, USA. ${ }^{3}$ Department of Biostatistics and Bioinformatics, Fox Chase Cancer Center, 333 Cottman
Avenue, Philadelphia, PA 19111, USA. ${ }^{4}$ Department of Clinical Genetics, Fox Chase Cancer Center, 333 Cottman Avenue, Philadelphia, PA 19111, USA. ${ }^{5}$ Will2Love LLC, 1333 Old Spanish Trail, Suite G, \#134, Houston, TX 77054, USA. ${ }^{6}$ Department of Psychology, Michigan State University, 316 Physics Road, Room 262, East Lansing, Ml 48824, USA. Department of Medicine-Oncology, Duke University Medical Center, DUMC 3459, Durham, NC 27710, USA. ${ }^{8}$ Department of Psychiatry \& Behavioral Sciences, Duke University Medical Center, DUMC 90399, Durham, NC 27708, USA.

\section{Received: 3 September 2019 Accepted: 9 December 2019}

Published online: 12 February 2020

\section{References}

1. American Cancer Society. Breast Cancer Facts \& Figures 2017-2018. Atlanta: American Cancer Society, Inc:; 2017

2. Reese JB, Shelby RA, Keefe FJ, Porter LS, Abernethy AP. Sexual concerns in cancer patients: a comparison of $\mathrm{Gl}$ and breast cancer patients. Support Care Cancer. 2010;18:1179-89.

3. Sadovsky R, Basson R, Krychman M, Morales AM, Schover L, Wang R, Incrocci L. Cancer and sexual problems. J Sex Med. 2010;7:349-73.

4. Panjari M, Bell RJ, Davis SR. Sexual function after breast cancer. J Sex Med. 2011;8:294-302.

5. Raggio GA, Butryn ML, Arigo D, Mikorski R, Palmer SC. Prevalence and correlates of sexual morbidity in long-term breast cancer survivors. Psychol Health. 2014;29:632-50.

6. Alder J, Zanetti R, Wight E, Urech C, Fink N, Bitzer J. Sexual dysfunction after premenopausal stage I and || breast cancer: do androgens play a role? I Sex Med. 2008;5:1898-906.

7. Meyerowitz BE, Desmond KA, Rowland JH, Wyatt GE, Ganz PA. Sexuality following breast cancer. J Sex Marital Ther. 1999;25:237-50.

8. Burwell SR, Case LD, Kaelin C, Avis NE. Sexual problems in younger women after breast cancer surgery. J Clin Oncol. 2006;24:2815-21.

9. Fobair P, Stewart SL, Chang SB, D'Onofrio C, Banks PJ, Bloom JR. Body image and sexual problems in young women with breast cancer. Psychooncology. 2006:15:579-94.

10. Nano MT, Gill PG, Kollias J, Bochner MA, Malycha P, Winefield HR. Psychological impact and cosmetic outcome of surgical breast cancer strategies. ANZ J Surg. 2005;75:940-7.

11. Loaring JM, Larkin M, Shaw R, Flowers P. Renegotiating sexual intimacy in the context of altered embodiment: the experiences of women with breast cancer and their male partners following mastectomy and reconstruction. Health Psychol. 2015;34:426-36.

12. Gilbert E, Ussher JM, Perz J. Sexuality after breast cancer: a review. Maturitas. 2010;66:397-407.

13. Bredart A, Dolbeault S, Savignoni A, Besancenet C, This P, Giami A, et al. Prevalence and associated factors of sexual problems after early-stage breast cancer treatment: results of a French exploratory survey. Psychooncology. 2011;20:841-50.

14. Schover LR, Baum GP, Fuson LA, Brewster A, Melhem-Bertrandt A. Sexual problems during the first two years of adjuvant treatment with aromatase inhibitors. J Sex Med. 2014;11:3102-11.

15. Fobair P, Spiegel D. Concerns about sexuality after breast cancer. Cancer J. 2009;15:19-26.

16. Ganz PA, Kwan L, Stanton AL, Krupnick JL, Rowland JH, Meyerowitz BE, Bower JE, Belin TR. Quality of life at the end of primary treatment of breast cancer: first results from the moving beyond cancer randomized trial. J Natl Cancer Inst. 2004;96:376-87.

17. Tevaarwerk AJ, Wang M, Zhao F, Fetting JH, Cella D, Wagner LI, et al. Phase III comparison of tamoxifen versus tamoxifen plus ovarian function suppression in premenopausal women with node-negative, hormone receptor-positive breast cancer (E-3193, INT-0142): a trial of the Eastern Cooperative Oncology Group. J Clin Oncol. 2014;32:3948-58.

18. Djohan R, Gage E, Gatherwright J, Pavri S, Firouz J, Bernard S, Yetman R. Patient satisfaction following nipple-sparing mastectomy and immediate breast reconstruction: an 8-year outcome study. Plast Reconstr Surg. 2010;125:818-29.

19. Otterburn DM, Sikora KE, Losken A. An outcome evaluation following postmastectomy nipple reconstruction using the C-V flap technique. Ann Plast Surg. 2010;64:574-8.

20. Reese JB, Porter LS, Casale KE, Bantug ET, Bober SL, Schwartz SC, Smith KC. Adapting a couple-based intimacy enhancement intervention to breast cancer: a developmental study. Health Psychol. 2016;35:1085-96. 
21. Ganz PA, Desmond KA, Belin TR, Meyerowitz BE, Rowland JH. Predictors of sexual health in women after a breast cancer diagnosis. J Clin Oncol. 1999;17:2371-80.

22. Speer JJ, Hillenberg B, Sugrue DP, Blacker C, Kresge CL, Decker VB, Zakalik D, Decker DA. Study of sexual functioning determinants in breast cancer survivors. Breast J. 2005;11:440-7.

23. Ganz PA, Desmond KA, Leedham B, Rowland JH, Meyerowitz BE, Belin TR. Quality of life in long-term, disease-free survivors of breast cancer: a followup study. J Natl Cancer Inst. 2002;94:39-49.

24. Andersen BL. In sickness and in health: maintaining intimacy after breast cancer recurrence. Cancer J. 2009:15:70-3.

25. Frechette D, Paquet L, Verma S, Clemons M, Wheatley-Price P, Gertler SZ, Song $X$, Graham N, Dent S. The impact of endocrine therapy on sexual dysfunction in postmenopausal women with early stage breast cancer: encouraging results from a prospective study. Breast Cancer Res Treat. 2013;141:111-7.

26. Ussher J, Perz J, Gilbert E. Changes to sexual well-being and intimacy after breast cancer. Cancer Nurs. 2012;35:456-64.

27. Carroll AJ, Baron SR, Carroll RA. Couple-based treatment for sexual problems following breast cancer: a review and synthesis of the literature. Support Care Cancer. 2016;24:3651-9.

28. Christensen DN. Post-mastectomy couple counseling: an outcome study of a structured treatment protocol. J Sex Marital Ther. 1983:9:266-75.

29. Scott JL, Halford WK, Ward BG. United we stand? The effects of a couplecoping intervention on adjustment to early stage breast or gynecological cancer. J Consult Clin Psychol. 2004;72:1122-35.

30. Baucom D, Porter L, Kirby J, Gremore T, Wiesenthal N, Aldridge W. A couplebased intervention for female breast cancer. Psychooncology. 2009;18:276-83.

31. Taylor S, Harley C, Ziegler L, Brown J, Velikova G. Interventions for sexual problems following treatment for breast cancer: a systematic review. Breast Cancer Res Treat. 2011;130:711-24.

32. Scott JL, Kayser K. A review of couple-based interventions for enhancing women's sexual adjustment and body image after cancer. Cancer J. 2009;15:48-56.

33. Brotto LA, Yule M, Breckon E. Psychological interventions for the sexual sequelae of cancer: a review of the literature. J Cancer Surviv. 2010;4:346-60.

34. Barbera L, Zwaal C, Elterman D, McPherson K, Wolfman W, Katz A, Matthew A, Interventions to Address Sexual Problems in Peole with Cancer Guideline Development Group. Interventions to address sexual problems in people with cancer. Curr Oncol. 2017;24:192-200.

35. Seav SM, Dominick SA, Stepanyuk B, Gorman JR, Chingos DT, Ehren JL, Krychman ML, Su HI. Management of sexual dysfunction in breast cancer survivors: a systematic review. Womens Midlife Health. 2015;1:1-27.

36. Chen J, Geng L, Song X, Li H, Giordan N, Liao Q. Evaluation of the efficacy and safety of hyaluronic acid vaginal gel to ease vaginal dryness: a multicenter, randomized, controlled, open-Label, parallel-group, clinical trial. J Sex Med. 2013;10:1575-84.

37. Stute P. Is vaginal hyaluronic acid as effective as vaginal estriol for vaginal dryness relief? Arch Gynecol Obstet. 2013;288:1199-201.

38. Carter J, Goldfrank D, Schover LR. Simple strategies for vaginal health promotion in cancer survivors. J Sex Med. 2011;8:549-59.

39. Goetsch MF, Lim JY, Caughey AB. A practical solution for dyspareunia in breast cancer survivors: a randomized controlled trial. J Clin Oncol. 2015;33: 3394-400.

40. Hummel SB, Hahn DEE, van Lankveld JJDM, Oldenburg HSA, Broomans E, Aaronson NK. Factors associated with specific Diagnostic and Statistical Manual of Mental Disorders, Fourth Edition sexual dysfunctions in breast cancer survivors: a study of patients and their partners. J Sex Med. 2017;14:1248-59.

41. Ussher JM, Perz J, Gilbert E. Information needs associated with changes to sexual well-being after breast cancer. J Adv Nurs. 2012;69:327-37.

42. Hummel SB, van Lankveld JJ, Oldenburg HS, Hahn DE, Kieffer JM, Gerritsma $M A$, et al. Efficacy of Internet-based cognitive behavioral therapy in improving sexual functioning of breast cancer survivors: results of a randomized controlled trial. J Clin Oncol. 2017;35:1329-40.

43. Schover LR, Yuan Y, Fellman BM, Odensky E, Lewis PE, Martinetti P. Efficacy trial of an Internet-based intervention for cancer-related female sexual dysfunction. J Natl Compr Cancer Netw. 2013;11:1389-97.

44. Bandura A. Social foundations of thought and action: a social cognitive theory. Englewood Cliffs: Prentice Hall; 1986.

45. Bandura A. Health promotion from the perspective of social cognitive theory. Psychol Health. 1998;13:623-49.

46. Lusczynska A, Schwartzer R. Social cognitive theory. In: Conner M, Norman P, editors. Predicting health behavior: research and practice with social cognition models. 2nd ed. Maidenhead: Open University Press; 2005. p. 127-69.
47. Stanton AL, Luecken LJ, MacKinnon DP, Thompson EH. Mechanisms in psychosocial interventions for adults living with cancer: opportunity for integration of theory, research, and practice. J Consult Clin Psychol. 2013;81: 318-35.

48. Weber BA, Roberts BL, Resnick M, Deimling G, Zauszniewski JA, Musil C, Yarandi HN. The effect of dyadic intervention on self-efficacy, social support, and depression for men with prostate cancer. Psychooncology. 2004;13:47-60.

49. Epstein NB, Baucom DH. Enhanced cognitive behavioral therapy for couples: a contextual approach. Washington, DC: American Psychological Association; 2002.

50. Baucom DH, Porter LS, Kirby JS, Hudepohl J. Couple-based interventions for medical problems. Behav Ther. 2012;43:61-76.

51. Masters WH, Johnson VE. Human sexual inadequacy. Boston: Little, Brown \& Company; 1970

52. Leiblum SR. Principles and practice of sex therapy. 4th ed. New York: Guilford Press; 2007.

53. Barsky Reese J, Porter LS, Regan KR, Keefe FJ, Azad NS, Diaz LA Jr, Herman $J M$, Haythornthwaite JA. A randomized pilot trial of a telephone-based couples intervention for physical intimacy and sexual concerns in colorectal cancer. Psychooncology. 2014;23:1005-13.

54. Reese JB, Porter LS, Somers TJ, Keefe FJ. Pilot feasibility study of a telephone-based couples intervention for physical intimacy and sexual concerns in colorectal cancer. J Sex Marital Ther. 2012;38:402-17.

55. Reese JB, Smith KC, Handorf E, Sorice K, Bober SL, Bantug ET, Schwartz SC, Porter LS. A randomized pilot trial of a couple-based telephone intervention addressing sexual concerns for breast cancer survivors. J Psychosoc Oncol. 2019;37:242-63.

56. Ganz PA, Rowland JH, Desmond K, Meyerowitz BE, Wyatt GE. Life after breast cancer: understanding women's health-related quality of life and sexual functioning. J Clin Oncol. 1998;16:501-14.

57. Wyatt GE, Desmond KA, Ganz PA, Rowland JH, Ashing-Giwa K, Meyerowitz $B E$. Sexual functioning and intimacy in African American and white breast cancer survivors: a descriptive study. Womens Health. 1998;4:385-405.

58. Giedzinska AS, Meyerowitz BE, Ganz PA, Rowland JH. Health-related quality of life in a multiethnic sample of breast cancer survivors. Ann Behav Med. 2004:28:39-51.

59. Lewis PE, Sheng M, Rhodes MM, Jackson KE, Schover LR. Psychosocial concerns of young African American breast cancer survivors. J Psychosoc Oncol. 2012;30:168-84

60. Reese JB, Shelby RA, Abernethy AP. Sexual concerns in lung cancer patients: an examination of predictors and moderating effects of age and gender. Support Care Cancer. 2011;19:161-5.

61. Moher D, Hopewell S, Schulz KF, Montori V, Gøtzsche PC, Devereaux PJ, Elbourne D, Egger M, Altman DG. CONSORT 2010 Explanation and Elaboration: updated guidelines for reporting parallel group randomised trials. BMJ. 2010;340:8869.

62. Chan A-W, Tetzlaff JM, Altman DG, Laupacis A, Gøtzsche PC, Krleža-Jerić K et al. SPIRIT 2013 Statement: Defining Standard Protocol Items for Clinical Trials. Ann Intern Med. 2013;158:200-7.

63. Abernethy AP, Herndon JE II, Wheeler JL, Day JM, Hood L, Patwardhan M, Shaw $H$, Lyerly HK. Feasibility and acceptability to patients of a longitudinal system for evaluating cancer-related symptoms and quality of life: pilot study of an e/tablet data-collection system in academic oncology. J Pain Symptom Manag. 2009:37:1027-38.

64. Oken MM, Creech RH, Tormey DC, Horton J, Davis TE, McFadden ET, Carbone PP. Toxicity and response criteria of the Eastern Cooperative Oncology Group. Am J Clin Oncol. 1982;5:649-55.

65. Fredman SJ, Baucom DH, Gremore TM, Castellani AM, Kallman TA, Porter LS, et al. Quantifying the recruitment challenges with couple-based interventions for cancer: applications to early-stage breast cancer. Psychooncology. 2009;18:667-73.

66. Dagan $M$, Hagedoorn M. Response rates in studies of couples coping with cancer: a systematic review. Health Psychol. 2014;33:845-52.

67. Rosen R, Brown C, Heiman J, Leiblum S, Meston C, Shabsigh R, Ferguson D, D'Agostino R Jr. The Female Sexual Function Index (FSFI): a multidimensional self-report instrument for the assessment of female sexual function. J Sex Marital Ther. 2000;26:191-208.

68. Baser RE, Li Y, Carter J. Psychometric validation of the Female Sexual Function Index (FSFI) in cancer survivors. Cancer. 2012;118:4606-18.

69. Bartula I, Sherman KA. The Female Sexual Functioning Index (FSFI): evaluation of acceptability, reliability, and validity in women with breast cancer. Support Care Cancer. 2015;23:2633-41. 


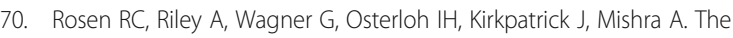
International Index of Erectile Function (IIEF): a multidimensional scale for assessment of erectile dysfunction. Urology. 1997;49:822-30.

71. Rosen RC, Cappelleri JC, Gendrano N 3rd. The International Index of Erectile Function (IIEF): a state-of-the-science review. Int J Impot Res. 2002;14:226-44.

72. DeRogatis L, Clayton A, Lewis-D'Agostino D, Wunderlich G, Fu Y. Validation of the Female Sexual Distress Scale-Revised for assessing distress in women with hypoactive sexual desire disorder. J Sex Med. 2008;5:357-64.

73. Hummel SB, van Lankveld JJ, Oldenburg HS, Hahn DE, Broomans E, Aaronson NK. Internet-based cognitive behavioral therapy for sexual dysfunctions in women treated for breast cancer: design of a multicenter, randomized controlled trial. BMC Cancer. 2015;15:321.

74. Miller RS, Lefcourt HM. The assessment of social intimacy. J Pers Assess. 1982;46:514-8

75. Porter LS, Keefe FJ, Baucom DH, Hurwitz H, Moser B, Patterson E, Kim HJ. Partner-assisted emotional disclosure for patients with gastrointestinal cancer. Cancer. 2009;115:4326-38.

76. Porter LS, Keefe FJ, Baucom DH, Olsen M, Zafar SY, Uronis H. A randomized pilot trial of a videoconference couples communication intervention for advanced Gl cancer. Psychooncology. 2017;26:1027-35.

77. Hunsley J, Pinsent C, Lefebvre M, James-Tanner S, Vito D. Construct validity of the short forms of the Dyadic Adjustment Scale. Fam Relat. 1995;44:231.

78. Hunsley J, Best M, Lefebvre M, Vito D. The Seven-Item Short Form of the Dyadic Adjustment Scale: further evidence for construct validity. Am J Fam Ther. 2001;29:325-35.

79. Badr H, Shen MJ. Pain catastrophizing, pain intensity, and dyadic adjustment influence patient and partner depression in metastatic breast cancer. Clin J Pain. 2014;30:923-33.

80. Kroenke K, Spitzer RL, Williams JB. The PHQ-9: validity of a brief depression severity measure. J Gen Intern Med. 2001;16:606-13.

81. Spitzer RL, Kroenke K, Williams JB, Lowe B. A brief measure for assessing generalized anxiety disorder: the GAD-7. Arch Intern Med. 2006;166:1092-7.

82. Thekkumpurath P, Walker J, Butcher I, Hodges L, Kleiboer A, O'Connor M, et al. Screening for major depression in cancer outpatients: the diagnostic accuracy of the 9-item patient health questionnaire. Cancer. 2011;117:218-27.

83. Bandura A. Guide for constructing self-efficacy scales. In: Pajares F, Urdan T, editors. Self-efficacy beliefs of adolescents. Greenwich: Information Age Publishing; 2006. p. 307-38.

84. Catania J. Dyadic Sexual Communication Scale. In: Fisher TD, Davis CM, Yarber WL, Davis SL, editors. Handbook of sexuality-related measures. 3rd ed. Routledge: New York; 2011. p. 130-1.

85. Garos S, Kluck A, Aronoff D. Prostate cancer patients and their partners: differences in satisfaction indices and psychological variables. J Sex Med. 2007:4:1394-403.

86. Borkovec TD, Nau SD. Credibility of analogue therapy rationales. J Behav Ther Exp Psychiatry. 1972;3:257-60.

87. Rosen RC, Barsky JL. Normal sexual response in women. Obstet Gynecol Clin N Am. 2006;33:515-26.

88. Masters WH, Johnson VE. Principles of the new sex therapy. Am J Psychiatry. 1976;133:548-54.

89. Reese JB, Keefe FJ, Somers TJ, Abernethy AP. Coping with sexual concerns after cancer: the use of flexible coping. Support Care Cancer. 2010;18:785-800.

90. Barsky JL, Friedman MA, Rosen RC. Sexual dysfunction and chronic illness: the role of flexibility in coping. J Sex Marital Ther. 2006;32:235-53.

91. Poulsen SS, Thomas V. Cultural issues in couple therapy. J Couple Relat Ther. 2007;6:141-52.

92. McGoldrick M, Loonan E, Wohlsifer D. Sexuality and culture. In: Leiblum S, editor. Principles and practice of sex therapy. 4th ed. New York: The Guilford Press; 2007. p. 416-41.

93. Gagnon JH, Rosen RC, Leiblum SR. Cognitive and social aspects of sexual dysfunction: sexual scripts in sex therapy. J Sex Marital Ther. 1982;8:44-56.

94. Cancer Support Community. Breast Cancer Specialty Registry Report 2017. Washington, DC: Cancer Support Community; 2017.

95. Berger AM, Gerber LH, Mayer DK. Cancer-related fatigue: implications for breast cancer survivors. Cancer. 2012;118:2261-9.

96. Lang KM, Little TD. Principled missing data treatments. Prev Sci. 2018;19:284-94.

97. Van Buuren S. Flexible imputation of missing data. 2nd ed. Boca Raton: CRC/Chapman \& Hall; 2018.

98. van Buuren S, Groothuis-Oudshoorn K. mice: Multivariate Imputation by Chained Equations in R. J Stat Softw. 2011;45:67.
99. Wiegel M, Meston C, Rosen R. The Female Sexual Function Index (FSFI): cross-validation and development of clinical cutoff scores. J Sex Marital Ther. 2005;31:1-20.

100. Cappelleri JC, Rosen RC, Smith MD, Mishra A, Osterloh $\Vdash$. Diagnostic evaluation of the erectile function domain of the international index of erectile function. Urology. 1999;54:346-51.

101. Kenny DA, Cook W. Partner effects in relationship research: conceptual issues, analytic difficulties, and illustrations. Pers Relat. 1999;6:433-48.

102. Valeri L, Vanderweele TJ. Mediation analysis allowing for exposure-mediator interactions and causal interpretation: theoretical assumptions and implementation with SAS and SPSS macros. Psychol Methods. 2013;18:137-50.

103. VanderWeele TJ. Mediation analysis: a practitioner's guide. Annu Rev Public Health. 2016;37:17-32.

104. Hill EK, Sandbo S, Abramsohn E, Makelarski J, Wroblewski K, Wenrich ER, et al. Assessing gynecologic and breast cancer survivors' sexual health care needs. Cancer. 2011;117:2643-51.

105. Moyer A, Goldenberg M, Hall MA, Knapp-Oliver SK, Sohl SJ, Sarma EA, Schneider S. Mediators of change in psychosocial interventions for cancer patients: a systematic review. Behav Med. 2012;38:90-114.

\section{Publisher's Note}

Springer Nature remains neutral with regard to jurisdictional claims in published maps and institutional affiliations.
Ready to submit your research? Choose BMC and benefit from:

- fast, convenient online submission

- thorough peer review by experienced researchers in your field

- rapid publication on acceptance

- support for research data, including large and complex data types

- gold Open Access which fosters wider collaboration and increased citations

- maximum visibility for your research: over $100 \mathrm{M}$ website views per year

At BMC, research is always in progress.

Learn more biomedcentral.com/submissions 